\title{
A case of denosumab-induced hypocalcaemia in a patient with non-metastatic prostate cancer and renal impairment
}

\author{
${ }^{1} \mathrm{~S}$ Blackley, ${ }^{2} \mathrm{~K}$ Anderson, ${ }^{3} \mathrm{~J}$ Berg \\ ${ }^{1}$ Medicine of the Elderly Registrar, ${ }^{2}$ Medicine of the Elderly Consultant, ${ }^{3}$ Osteoporosis Nurse Specialist, Western General Hospital, Edinburgh, \\ UK
}

\begin{abstract}
Denosumab is an emerging new treatment for osteoporosis in postmenopausal women and men with non-metastatic prostate cancer. It is largely used by specialists as an alternative treatment in patients with contraindications to traditional, more commonly used drugs such as bisphosphonates. One important side effect is hypocalcaemia, which may be life threatening. The risk of this is increased in renal impairment, mainly if eGFR $<30$ $\mathrm{ml} / \mathrm{min} / 1.73 \mathrm{~m}^{2}$, and is exacerbated by vitamin $D$ insufficiency.

This is a case study of prolonged symptomatic hypocalcaemia after a single dose of denosumab in a patient with non-metastatic prostate cancer and moderate renal impairment (eGFR $40 \mathrm{ml} / \mathrm{min} / 1.73 \mathrm{~m}^{2}$ ). The patient presented with acute confusion, muscle cramps and myoclonic jerks 5 weeks after treatment. This case demonstrates the need to be aware of adverse effects of denosumab in mildmoderate renal impairment and the need to monitor calcium levels pre- and post-treatment.
\end{abstract}

Correspondence to S Blackley Medicine of the Elderly Department Royal Victoria Building Western General Hospital Crewe Road South Edinburgh EH4 2XU UK

e-mail sam.blackley@nhslothian. scot.nhs.uk

KEYWORDS denosumab, hypocalcaemia, prostate cancer, renal impairment

DECLARATION OF INTERESTS No conflict of interest declared.

\section{INTRODUCTION}

Older patients often present to acute receiving units with confusion and it can be challenging to source accurate information about recent history or medications. It is becoming more common for some medications to be dispensed by specialists only, e.g. chemotherapy agents, monoclonal antibodies and subcutaneous or intravenous forms of bone protection.

An example of one such treatment is denosumab, used for postmenopausal osteoporosis' and for patients with bone metastases from solid tumours. ${ }^{2}$ It is a human monoclonal antibody against receptor activator of nuclear factor-kB ligand (RANKL) and is generally prescribed to patients with osteoporosis as one injection to be given every 6 months for at least 5 years. Activation of RANK by RANKL promotes the maturation of pre-osteoclasts into osteoclasts. Denosumab inhibits this maturation of osteoclasts by binding to and inhibiting RANKL. This reduces release of calcium from the skeleton. Hypocalcaemia, which is a side effect of denosumab treatment and may be lifethreatening, ${ }^{3}$ is thought to be more likely to occur in individuals with chronic kidney disease due to decreased levels of I-alpha-hydroxylated vitamin D metabolites.

It is recommended that, prior to commencing treatment, 25-hydroxy-vitamin $D$ levels are measured and replacement is given. ${ }^{4} \mathrm{It}$ is also important that patients are aware of the importance of adherence to calcium and vitamin $D$ supplements while undergoing treatment. This treatment is used, in particular, in patients who have severe renal impairment, (eGFR $<35 \mathrm{ml}$ / $\min / 1.73 \mathrm{~m}^{2}$ ) where alternative agents such as bisphosphonates may be contraindicated, or where people cannot tolerate the gastrointestinal side effects, and its specialist use means that adverse effects may be less widely known. The FREEDOM trial initially showed denosumab was not associated with an increase in adverse events among patients with renal impairment. ${ }^{5}$ However, evidence is emerging to suggest this is not the case. As it is prescribed infrequently, the awareness of side effects in nonspecialist areas may be reduced. For example, in NHS Lothian (with an estimated osteoporotic population of 700,000 ) there are currently $I 5 I$ patients receiving denosumab [personal communication with JB].

\section{CASE REPORT}

An 85-year-old man presented with acute confusion, muscle cramps and myoclonic jerks. His past medical history included osteoporosis and prostate cancer treated with goserelin. Other comorbidities included monoclonal gammopathy of unknown significance, mild left ventricular systolic dysfunction, severe visual impairment and gastric ulceration. 
His medications were senna, ferrous fumarate, and calcium and vitamin $D$ supplementation in the form of Adcal D3 forte (one tablet twice daily). These were administered via a dosette box and supervised by carers who attended four times a day. On physical examination he was confused and had obvious intermittent myoclonic jerks and carpopedal spasm. He complained of perioral paraesthesia but Chvostek's sign was not elicited.

Blood tests confirmed moderate renal impairment (urea $12.0 \mathrm{mmol} / \mathrm{L}$, creatinine $157 \mu \mathrm{mol} / \mathrm{L}$, eGFR $40 \mathrm{ml} /$ $\mathrm{min} / 1.73 \mathrm{~m}^{2}$ ) with a total albumin adjusted calcium level of $1.32 \mathrm{mmol} / \mathrm{L}$ (normal range $2.1-2.6 \mathrm{mmol} / \mathrm{L}$ ), phosphate $0.66 \mathrm{mmol} / \mathrm{L}$ (0.8-I.4), parathyroid hormone $28.0 \mathrm{pmol} / \mathrm{L}$ ( I.I-6.8 pmol/L), albumin $33 \mathrm{~g} / \mathrm{L}(30-45)$, alkaline phosphatase $107 \mathrm{U} / \mathrm{L}$ (40-125). A 25-hydroxyvitamin D level had not been recorded in his laboratory series before or after treatment with denosumab.

The cause of the hypocalcaemia was unclear at presentation until a review of his old case notes revealed he had been given his first dose of denosumab 5 weeks earlier. His renal function and total calcium levels were measured I month prior to administration of denosumab. He received several intravenous infusions of $10 \%$ calcium gluconate over the following 8 weeks in order to correct his electrolytes and resolve his symptoms. These were initially administered as intermittent daily infusions of $100 \mathrm{ml}$ of $10 \%$ calcium gluconate for the first week, and calcium levels were checked daily. He then received further $10 \mathrm{ml}$ infusions of $10 \%$ calcium gluconate as required when his calcium level fell below $2.1 \mathrm{mmol} / \mathrm{L}$. He continued on three tablets twice daily of oral Sandocal (calcium gluconate/ calcium carbonate $=25 \mathrm{mmol} \mathrm{Ca}{ }^{2+}$ ) for a further month until his corrected calcium level rose to $2.88 \mathrm{mmol} / \mathrm{L}$. $\mathrm{He}$ was then maintained on oral calcium and vitamin $D$ (one tablet twice daily $=15 \mathrm{~mol} \mathrm{Ca}{ }^{2+}$ per tablet and 400 units colecalciferol). Following this, his confusion was much improved and he underwent rehabilitation and discharge home.

\section{DISCUSSION}

Previous reports suggest a variable incidence of denosumab-induced hypocalcaemia., ${ }^{2,-9}$ Clinical trials in patients with advanced prostate cancer report a higher frequency of hypocalcaemia with denosumab, compared to the alternative drug, zoledronic acid (I3\% vs $6 \% \mathrm{p}$ $<0.000 \mathrm{I}) .{ }^{8}$ There is also a greater risk of hypocalcaemia with renal impairment $(24 \%$ with an eGFR $<30 \mathrm{ml} / \mathrm{min}$, $3 \%$ with an eGFR of $>30 \mathrm{ml} / \mathrm{min}){ }^{9}$. Patients who develop hypocalcaemia may have a protracted stay in hospital as the half life of denosumab is 26 days.

Hypocalcaemia was not initially reported as a concerning adverse event but the Medicines and Healthcare products Regulatory Agency ${ }^{3}$ issued a warning after three deaths associated with denosumab-induced hypocalcaemia, and released a further update in September $2014^{10}$ highlighting the importance of monitoring for hypocalcaemia. They have now received 66 Yellow Card reports of hypocalcaemia in patients receiving denosumab. In order to minimise this risk it is recommended that patients receive daily calcium and vitamin D supplementation.These new recommendations describe different approaches depending on the dosage of drug commenced and degree of renal impairment. This includes calcium and 25-hydroxyvitamin $D$ levels prior to initiation for both the $60 \mathrm{mg}$ and $120 \mathrm{mg}$ doses, and 2 weeks after initial dose but only for those commenced on $120 \mathrm{mg}$.

Our patient received a $60 \mathrm{mg}$ dose, had only moderate renal impairment yet still developed symptoms. This may have been due to undiagnosed vitamin $D$ insufficiency as his levels were not measured, however we suggest it would be good practice to measure calcium and vitamin $\mathrm{D}$ levels pre- and post-treatment for any degree of renal impairment.

This case also highlights the importance of compliance with vitamin $\mathrm{D}$ and calcium supplementation, and consideration of the likelihood of this with the patient before commencing treatment with denosumab. It has been suggested that intermittent high dose oral vitamin D3 should be used as replacement prior to commencing potent antiresorptive agents such as denosumab when there is pre-treatment vitamin $D$ insufficiency to increase the adherence to medication." Adherence to calcium and vitamin D treatment is often poor, secondary to gastrointestinal side effects with a previous study showing only $59 \%$ of patients took calcium and vitamin D tablets more than $80 \%$ of the time. ${ }^{12}$ In vitamin $D$ deficiency, using high dose replacement $(300,000$ units of cholecalciferol over 6-10 weeks) can be helpful in treating hypocalcaemia. ${ }^{13}$ Unfortunately this was not used in our case.

As mentioned in the introduction, denosumab is used by specialists and so it may not be immediately obvious when a patient is admitted to hospital that this is a current medication. This is becoming a more frequent occurrence with medications used in oncology, rheumatology and dementia services not being listed in GP records. Robust recording methods and flagging of these medications to general practitioners is therefore required.

\section{KEY POINTS}

- Denosumab is a new treatment for osteoporosis and bony metastases and is being used by specialists as an alternative to bisphosphonates in those with renal impairment. It is important that intermittently prescribed specialist medications used in secondary 
care are highlighted to general practitioners.

- It is a recognised cause of hypocalcaemia and this risk is higher in those with impaired renal function.

- Current recommendations suggest monitoring calcium levels in patients with an eGFR of $<30 \mathrm{ml} /$ $\min$. However, this case suggests it may be appropriate to monitor for any degree of renal impairment.

- Adherence to calcium and vitamin D supplementation is poor and high dose intermittent use of oral vitamin D3 should be considered if adherence is an issue.

\section{REFERENCES}

I Cummings SR, Martin JS, McClung MR et al. Denosumab for prevention of fractures in postmenopausal women with osteoporosis. N Engl J Med 2009; 36I: 756-65. http://dx.doi. org/I 0.1056/NEJMoa0809493

2 Smith MR, Egerdie B, Hernández-Toriz $\mathrm{N}$ et al. Denosumab in men receiving androgen-deprivation therapy for prostate cancer. $\mathrm{N}$ Engl J Med 2009; 36I: 745-55. http://dx.doi.org//0.1056/ NEJMoa0809003

3 MHRA. Denosumab: Fatal cases of severe symptomatic hypocalcaemia, and risk of hypocalcaemia at any time during treatment - monitoring recommended. Drug Safety Update, 30 October 20I2. https://www. gov.uk/drug-safety-update/denosumab-monitoring-recommended (accessed 26/3/20I5)

4 Joint Formulary Committee. British National Formulary. 64th ed. London: BMJ Group and Pharmaceutical Press; 2012

5 Talreja DB. Severe hypocalcaemia following a single injection of denosumab in a patient with renal impairment. Journal of Drug Assessment 2012; I: 30-3. http://dx.doi.org/I0.3109/2I556660.20I 2.668504

6 Stopeck AT, Lipton A, Body JJ et al. Denosumab compared with zoledronic acid for the treatment of bone metastases in patients with advanced breast cancer: a randomized, double-blind study.J Clin Oncol 2010; 28: 5I32-9. http://dx.doi.org/I0.1200/ |CO.2010.29.7I01

7 Henry DH, Costa L, Goldwasser F et al. Randomized, double-blind study of denosumab versus zoledronic acid in the treatment of bone metastases in patients with advanced cancer (excluding breast and prostate cancer) or multiple myeloma. J Clin Oncol 20I I; 29: I I25-32. http://dx.doi.org/I0.1200/JCO.20I0.3I.3304

\section{ACKNOWLEDGEMENTS}

The authors would like to thank Dr Andrew McLaren for his support.

8 Fizazi K, Carducci M, Smith M et al. Denosumab versus zoledronic acid for treatment of bone metastases in men with castrationresistant prostate cancer: a randomised, double-blind study. Lancet 2011; 377: 813-22. http://dx.doi.org/l0.1016/S0I406736(I0)62344-6

9 Block GA, Bone HG, Fang L et al. A single-dose study of denosumab in patients with various degrees of renal impairment. J Bone Miner Res 20I2; 27: I47I-9. http://dx.doi.org/I0.I002/ jbmr.1613

10 MHRA. Denosumab: Minimising the risk of osteonecrosis of the jaw; monitoring for hypocalcaemia. Drug Safety Update, 25 September 20I4. https://www.gov.uk/drug-safety-update/denosumabupdated-recommendations (accessed 26/3/2015).

II National Osteoporosis Society. Vitamin D and Bone Health: A Practical Clinical Guideline for Patient Management. April 2013. https://www.nos.org.uk/document.doc?id=1352 (accessed 26/320I5).

12 Jackson RD, LaCroix AZ, Gass $M$ et al. Calcium plus vitamin D supplementation and the risk of fractures. N Engl J Med 2006; 354 : 669-83.

13 Society for Endocrinology. Acute Hypocalcaemia. February 2013. http://www.endocrinology.org/policy/docs//3-02_ EmergencyGuidance-AcuteHypocalcaemia_(inAdults).pdf (accessed 26/3/20I5). 